\title{
A study of orofacial clefts seen in a tertiary referral hospital in Nepal
}

\author{
V P Singh ${ }^{1}$, J N Sharma ${ }^{1}$, D K Roy ${ }^{2}$, R K Roy ${ }^{3}$ \\ (Index words: cleft lip, cleft palate, epidemiology)
}

\begin{abstract}
Objectives Clefts of lip (CL), palate (CP), or both (CLP) are the most common orofacial congenital malformations found among live births, accounting for a large number of head and neck anomalies. To date, little is known regarding the epidemiology and pattern of orofacial clefts in Nepal. The objectives were to know the frequency and pattern of orofacial clefts in Eastern Nepal and compare with different parts of the world.
\end{abstract}

Methods A retrospective study was conducted at B P Koirala Institute of Health Sciences to identify all children with orofacial clefts who were treated during a period of five years. Cleft lip and/or palate records were obtained from patient files in the Hospital's Medical Record Department. Age at presentation, sex, region of origin, type and laterality of the cleft were recorded.

Results A total of 398 orofacial cleft cases were seen during the period. Isolated cleft lip $(\mathrm{CL})$ was the most common cleft type followed closely by cleft palate (CP).

Conclusions The distribution of clefts by side showed a significant preponderance of the left side followed by the right and bilateral sides.

Ceylon Medical Journal 2012; 57: 84-85

\section{Introduction}

Cleft lip and palate is one of the most common congenital malformations. Cleft lip/palate have a wide geographic distribution with average live birth prevalence in the world ranging from 1/700 to 1/1000 births with substantial variability related to geographic origin, ethnicity, and socioeconomic conditions [1]. About 70\% of orofacial cleft cases are nonsyndromic, i.e. with affected individuals showing no other physical or developmental anomalies [2]. The frequency and distribution of orofacial clefts also varies widely among different populations. Although the epidemiology of cleft lip and palate has been studied extensively in different parts of the world, there is little information on the epidemiology of cleft deformities in Nepalese populations. The main objective of this study was to establish the frequency, laterality, sex and geographical distribution of orofacial clefts among patients attending B P Koirala Institute of Health Sciences (BPKIHS) in Dharan, Nepal.

\section{Methods}

A retrospective study was conducted at BPKIHS located in eastern part of Nepal in Dharan, from June 2005 to December 2010. BP Koirala Institute of Health Sciences is the only tertiary referral hospital in the eastern part of the country, serving a population of approximately more than 5 million people from over three zones (Koshi, Mechi, Sagarmatha) which comprises sixteen districts. Most patients with orofacial clefts in the surrounding regions are referred to this hospital as it is the only centre that offers surgical expertise to repair orofacial clefts on the eastern part of Nepal. Cleft lip and/or palate records were obtained from patient files in the Hospital's Medical Records Department. Age at presentation, sex, type and laterality of the cleft were recorded. Orofacial cleft cases that lacked some/any of the above information (e.g. type of cleft, laterality) were excluded. Cleft type was classified as 1. CL: cleft lip and alveolus (right, left, bilateral), 2. CLP: cleft lip and palate (right, left, bilateral), 3. CP: cleft palate (right, left, bilateral). SPSS version 15 was used to process the data and statistical analyses. Chi square test was used to test the association between variables.

\section{Results}

A total of 418 cases with orofacial cleft were seen between July 2005 and December 2010. Twenty cases with orofacial clefts had incomplete patient files, and thus were not included in the study. In 12 cases laterality could not be determined. The majority of cases came from Koshi zone followed by the Sagarmatha zone. The most common cleft type was isolated cleft lip (CL) constituting 49.74\% of all cleft deformities. Clefts of both lip and palate (CLP) and isolated cleft palate (CP) constituted $27.63 \%$ and $22.61 \%$ of cleft deformities respectively. Overall, females were slightly more affected than males among all clefts with a frequency of $56 \%$ and $47 \%$ respectively. However, the association between cleft type and sex was not statistically significant. The distribution of clefts by side showed a preponderance of the left side (48.96\%), followed by right side (23.57\%) and bilateral cases (20.46\%). Midline clefts accounted for only 6.99\% of all cleft cases (Table 1).

${ }^{1}$ Department of Orthodontics, College of Dental Surgery, BPKIHS, Dharan, ${ }^{2}$ Dental Surgeon, Dharan and ${ }^{3}$ School of Public Health, BPKIHS, Dharan, Nepal.

Correspondence: VPS, e-mail: <varundc@gmail.com>. Received 27 October 2011 and revised version accepted 16 March 2012. Competing interests: none declared. 
Table 1. Distribution of orofacial clefts according to type and sex

\begin{tabular}{lcccc}
\hline Cleft Cases & Total & Cleft lip & $\begin{array}{c}\text { Cleft lip } \\
\text { and palate }\end{array}$ & $\begin{array}{c}\text { Cleft } \\
\text { palate }\end{array}$ \\
\hline Total & 398 & 198 & 103 & 97 \\
Male & 175 & 87 & 49 & 39 \\
Female & 223 & 111 & 54 & 58 \\
$p$ value & & 0.990 & 0.392 & 0.390 \\
\hline
\end{tabular}

\section{Discussion}

In the present study isolated cleft lip was the most common cleft type, followed by clefts of both the lip and palate. These findings are in contrast to most studies in Caucasian and Asian populations that have reported higher frequency of isolated cleft palate and cleft of both palate and lip [2, 3]. Although some of this variation is attributable to differences in study design, analysis of comparable, small, retrospective or hospitalbased studies in low and middle income countries in Africa, Asia and South America suggests this variation may reflect a biological phenomenon $[4,5]$. The change in the pattern of clefts may also be due to the fact that only the cleft lip and palate patients will come to a hospital due to aesthetic reasons and isolated cleft palate patients will remain in the community without seeking treatment. The observed pattern of female predominance in cleft lip and clefts of both lip and palate is in contrast with data on Caucasian populations. However, isolated cleft palate was more common in females which are in accordance with most Caucasian series. The association between cleft type and laterality was statistically significant for cleft palate. The distribution of clefts by side showed a preponderance of the left side followed by right side and bilateral cases, midline clefts and was in accordance to Caucasian studies [5].

\section{References}

1. Mossey PA, Little J. Epidemiology of oral clefts: an international perspective, in cleft lip and palate. In: From Origins To Treatment. Edited by: Wyszynski DF. Oxford University Press: Oxford; 2002: 127-58.

2. Calzolari E, Pierini A, Astolfi G, Bianchi F, Neville AJ, Rivieri F. Associated anomalies in multi-malformed infants with cleft lip and palate: an epidemiologic study of nearly 6 million births in 23 EUROCAT registries. American Journal of Medical Genetics 2007; 143: 528-37.

3. Milerad J, Larson O, Hagberg C, Ideberg M. Associated malformations in infants with cleft lip and palate: a prospective, population-based study. Paediatrics 1997; 100: 180-6.

4. Onah II, Opara KO, Olaitan PB, Oqbonnaya IS. Cleft lip and palate repair: the experience from two West African sub-regional centres. Journal of Plastic Reconstructure and Aesthetic Surgery 2008; 61: 879-82.

5. Martelli-Junior H, Porto LV, Barbosa Martelli DS, Bonan PRF, Freitas AB, Coletta RD. Prevalence of nonsyndromic oral clefts in a reference hospital in the state of Minas Gerais, Brazil, between 2000-2005. Brazilian Oral Research 2007; 21: 314-7. 